\title{
WEB TOOLS AND TECHNOLOGIES TO INCREASE CITATION FREQUENCY BY USE OF SOCIAL MEDIA: AN APPRAISAL
}

\author{
Dr. Khaisar Muneebulla Khan ${ }^{*}{ }^{\square}$ (iD), Dr. K. S. Ali 2 (iD \\ ${ }^{1}$ Professor, Department of Library and Information Science, Yenepoya (Deemed to be University), \\ Deralakatte, Mangaluru. Professor \& Chairman (Rtd) Department of Library and Information \\ Science, Mangalore University-574199, India \\ ${ }^{2}$ Assistant Professor \& Deputy Librarian, Department of Library \& Information Science \& Central \\ Library, Yenepoya (Deemed to be University), Deralakatte, Mangaluru-575018, India
}

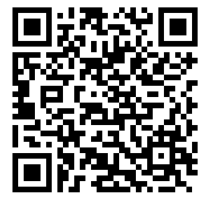

DOI: https://doi.org/10.29121/granthaalayah.v8.i10.2020.1587

Article Type: Research Article

Article Citation: Dr. Khaisar Muneebulla Khan, and Dr. K. S. Ali. (2020). WEB TOOLS AND TECHNOLOGIES TO INCREASE CITATION FREQUENCY BY USE OF SOCIAL MEDIA: AN APPRAISAL. International Journal of Research GRANTHAALAYAH, 8(10), 31-36. https://doi.org/10.29121/granthaa layah.v8.i10.2020.1587

Received Date: 1 October 2020

Accepted Date: 22 October 2020

Keywords:

Social Networking Sites

Social Media

Web Technologies

Citation Count

Citation Frequency

Researchers

Scholars

Scientists

\section{ABSTRACT}

Increasing technological advances and its applications in library and information centres and services have enabled users to access voluminous quality information through Internet. No doubt, World Wide Web (WWW) can be considered as one of the most innovative, magnificent and remarkable service of the 21st century. It has become most popular and convenient to share, publish, communicate and disseminate information instantly among researchers, scientist and academic community. The library profession, researchers and scientist are anonymous to agree that social networks and social media have completely revolutionise the ways and means to access, communicate share, and disseminate nascent thoughts, ideas, and information at much faster pace. This networking of information and communication facilities build rapport, connections and collaborations with peer groups, similar organisations and institutions which in turn promotes academic, research and development. The article provides in brief different networking resources, tools and techniques and the significant role of played by social media on researchers and scientist for academic progress and developments.

\section{INTRODUCTION}

\subsection{CITATION COUNT}

The qualitative and quantitative novel research findings, output and publications of any academic and research institutions based on standard criteria of evaluation reflects the quality of the research as well as the institution rating. In other words, the outcome of research in any institution or an organisation can be considered for its evaluation and standing amongst the similar institutions with the same objectives.

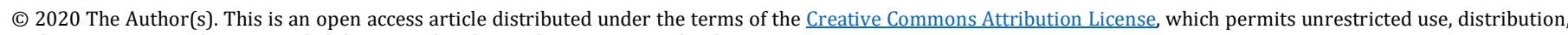
and reproduction in any medium, provided the original author and source are credited. 
Web Tools and Technologies to Increase Citation Frequency by Use of Social Media: An Appraisal

The number of citation of an article cited helps to rely on publications in as quality indicators that also show the quality of authors / contributor as well as the institution-author affiliation. The citation of article depends also on the visibility of the literature published. The post-publication of literature widely publicised facilitates its presence and visibility the relevant literature thereby helps to cite frequently particularly due to the internet and the open access publications accessibility.

\subsection{RESEARCH VISIBILITY}

Assessing the value of scientific research output, an important component of academic promotion and tenure is increasingly based on metrics such as the Impact Factor, H-index, and more recently Google Scholar that attempt to numerically encapsulate an author's productivity and scholarly impact. The H-index, discussed by AJNR Editor-inChief Mauricio Castillo in a 2010 editorial, and an expanding alphabet soup of additional measurement tools (Mindex, C-index, S-index, E-index, etc) are based on article citations accumulated over time. As such, it behoves researchers to consider avenues to expand the reach and visibility of their work. It is expected that article influence will soon be used by funding entities to assign monies for research. Social media represent a potential opportunity to do so and may be particularly important in an era in which the link between an article's citation rate and its publishing journal is in decline.

\subsection{SOCIAL MEDIA}

Social media is the connection of people in to specific group or group of people connecting with each other for dependency of information, ideas and exchange of information which can also be known as social networking. Social media simply refers to a process of connecting with group of people of same interest. However, the term social networking can be understood, as a composition of individuals, professionals or institutions attached with one another individuals to exchanges information. Social networking is possible anywhere, anytime or in any organisation say school, college, university, institution or in the work place among the individuals of the same group. The internet has made social networking more popular among individual and groups, to exchange their first hand experience, nascent thoughts and ideas, views and more importantly the any information as whole.

The online portal, or web service that attract to develop a social relationship among group of individual with same interests are a group of professionals interested in the same subject field is known as social networking sites. It is a relationship between individual with common or same purpose. It is an online community of users of the web. The services provided by social networking site based on a presentation of each individual social links and limitations of additional services. Social networking sites provide a large number of web based services to their users to interact each other through the internet i.e email, chatting, intent messaging etc. It is estimated that there are more than 200 social networking sites that are available on internet wherein the membership of this website are open to one and all. The correct use of social media web tools and technologies is definitely a blessing to the researchers and academician in this era of information proliferations and growth.

\section{SOCIAL MEDIA / NETWORKING PLATFORMS FOR RESEARCHERS}

Social media does not just benefit the general public, but also business people, scientists and researchers, students, and teachers. Social media marketing is a free method for authors, researchers, and scientists to reach out to the world and promote their work. It has now successfully become a marketing platform that offers benefits not only to researchers but also to their target audience. Social media provide a forum to promote your research to a wide audience and increase the opportunity of your publications being cited. The more links there are to your publications from different websites, the higher your publications will appear on search engine results pages.

\section{Advantages in using social media}

- It is easy to communicate effectively as well as efficiently

- It helps in exchange as well as transfer of knowledge/information

- It facilitates collaborative work

- It promotes exchange of inter-disciplinary information/knowledge

International Journal of Research -GRANTHAALAYAH 
- It helps cultivate creativity and new methodologies

- Finally, social media helps to promote research and its impact

\section{ACADEMIC SOCIAL NETWORKING SITES FOR RESEARCHERS}

\subsection{ACADEMIA.EDU}

Academic community / researcher / scientist can browse research article, exchange and disseminate their ideas quickly, intently, promote and publishes their research work by uploading in academia.edu. There are 71 million users registered in this academic social media. It helps in getting access scientist and researchers working throughout the world facilitating and promoting national and international collaboration to studies and research. It also has advantage for intently getting feedback from fellow scientist and researchers.

\subsection{RESEARCHGATE}

"ResearchGate is a wonderful social networking site designed intentionally for scientists and researchers to share their papers, ask to answer any questions, short reviews, research interests and find collaborators." On the basis of citation index, it provides academic score offering private chat rooms. Here, the scientist and researchers can exchange their ideas, findings, professional data / information maintaining confidentiality and secrecy of the topic discussed.

ResearchGate has over 17 million members in 205 countries as on May 2020. It was designed by and specifically for scientists, to meet their diverse needs, and is touted as Facebook for academics. Membership is free but is restricted to working scientists and academics (you need an academic institution email address). Full-text publications uploaded to ResearchGate profiles are indexed by Google Scholar.

\section{Advantages of ResearchGate and Academia.edu}

- Share publications

- Follow researchers

- View and discuss other researchers' publications

- Contact other researchers

- View job board

- Pose and answer questions

- Generate DOIs

- $\quad$ Sharing and viewing papers with other researchers

- Professional networking

- Indexed by Google Scholar

- Increasing citations

\section{SOCIAL CITATION MANAGEMENT TOOLS}

Citation Management Tools are able to store and manage citations to scholarly works you've been reading. Some of them also have the added feature of being academic social networking sites. You can join research specific interest groups, and share and discuss your research.

\subsection{MENDELEY}

A free downloadable citation management tool with online storage free up to 2 GB. (Additional storage space available for a fee) referring itself as an academic social network as well as a social manager too. It incorporates with Word and wide range of many applications. This platform can help you grow your network by joining groups of your interest. You can not only view your research impact but also view others popular works. 
Web Tools and Technologies to Increase Citation Frequency by Use of Social Media: An Appraisal

The features include creation a profile and sharing publications, need to follow other users and also join similar group, to frequently discuss publications of other peer group, give and also received relevant paper recommendation, participant in sharing and viewing other papers and to involving discursion thereby increasing professional networking and increasing the citations.

\subsection{CITEULIKE}

CiteULike is free tool helping in managing, sharing citations with fellow researcher and scientist. It facilitates users in storing, tagging and in the retrieval of required relevant information easily. Further, CiteULike stresses upon the importance and need of the social elements of citation sharing motivating the users to built contacts and fellowships with peer groups / fellow scientist and to know access and be informed of what is new in their library and information centres.

\section{GENERAL SOCIAL NETWORKING SITES}

1) Blogs: Blogs are also becoming more and more popular among researchers. As blogs can be accessed by the general public, they are a good way to widen your audience. Running a blog makes it possible to share your thoughts and research with a much wider audience, as well as receive comments and feedback. You can write detailed articles or research stories to engage your audience. You can also provide links to your work to increase visibility.

2) Twitter: You can use this platform to tweet about the latest research, blog, conference presentation, and more. You can also link your articles and other research publications in your tweets. Tweet links to new blog posts about your research. If appropriate, include a picture. It is more likely to be re-tweeted than just text.

3) Tumblr: It is blogging and social media tool which provides a stranded structure to Microblog conversations. You can attach videos, photos, links, and more about your research and add a short text message. E.g. linguistics

4) Facebook: Similar to other platforms, you can use it to update your followers and contacts with your latest work, blogs, presentations, and more. A younger generation of researchers are increasingly using Facebook to develop contacts and have academic exchanges

5) LinkedIn: It is a professional networking platform. You can use it share updates on your research or a paper in a specific group or publicly. You can also provide links to your blogs, articles, websites, and more.

6) SlideShare: Make slides about your publication easily available by uploading them to the web.

7) YouTube: Consider promoting your publications using YouTube videos. This will widen your audience.

\section{OTHER SOCIAL NETWORKING TOOLS}

\subsection{GOOGLE SCHOLAR}

"Google Scholar provides a simple way to broadly search for scholarly literature. From one place, you can search across many disciplines and sources: articles, theses, books, abstracts and court opinions, from academic publishers, professional societies, online repositories, universities and other web sites. Google Scholar helps you find relevant work across the world of scholarly research." Firstly, it's free, easy to search and easy to be found. Secondly, having a google scholar presence will allow anyone searching Google to find your work. This can be valuable, particularly when the person searching may be from the policy sector, industry, government or media rather than an academic.

\subsection{ORCID}

The ORCID (Open Researcher and Contributor ID) is A non-proprietary alphanumeric code which uniquely identifies scientific as well as the scientific authors and also the academic contributors is known as Open Researcher 
and Contributor ID that is ORCID. The ORCID is a unique identifier therefore it is single most important step which ensures the scientist work visibility attributed to his research. However, it has a difficulty with regard to publications in humanity and social science wherein the most personal names are not unique, have cultural differences in name order, contain the inconsistent use of first-name abbreviations and employ different writing systems. It provides a persistent identity for humans, which is same as that created for content-related entities on digital networks by digital object identifiers (DOIs).

\subsection{SUBSCRIBE TABLE OF CONTENTS ALERTS}

\subsubsection{TICTOCS}

If you subscribe to journal alerts via e-mail you can create rules to filter your e-mail into different folders rather than clogging your inbox. It may be an advantage to monitor journals from a single source like ticTOCs (http://www.tictocs.ac.uk/). so that you create one rule for that single source rather than many rules for each publisher's alerts.If staying up-to-the-minute is important to you, you might want to use ticTOCs or set up direct alerts from the journal publishers. Features of ticTOCs: freely available to everyone, 14,271 journal titles available, provides the table of contents (TOC) RSS feeds by title, subject or publisher, embedded links to full-text articles.

\subsubsection{SETTING UP JOURNALS ALERTS}

Journal alerts are notifications of new journal issues, new articles or tables of contents (TOC), delivered via email, RSS feed or aggregator at regular intervals. Similarly, search alerts like Google Alerts (http://www.google.com/alerts) can notify you of the latest new search results on a given topic. You can use both journals and search alerts to receive regular updates on the work happening in your field.

You can subscribe to alerts relevant to given search terms on databases which index journals (including those mentioned earlier: EBSCOhost, Web of Science and Proquest) as well as on Google and Google Scholar. To subscribe to alerts on Google: sign in to your Google account (or create an account if you don't have one). Go to Google alerts and then set up your relevant search alert. On Google Scholar (http://scholar.google.co.uk/), you can create an alert by first signing in and then be performing a search. You then click the 'Create email alert' link to create an alert for your specific search results.

Search alerts are especially useful if it's important to you to keep things simple: you can choose just one database or search engine to alert you to all relevant new content. Just make sure first that the database you're using carries the important journals for your field.

There are many advantages of using alerts. They are it saves time and energy as it is taking the effort of continuous browsing; makes to keep the researcher up to date with most recent and latest information as it notifies with alert; it manages the exponential information flood by filter rules and folders; since, the online edition/digitise form often comes out earlier than print version; the database and online journals facilitates reader to set up journal alter by Really Simple Syndication (RSS) feeds or even emails. Further, it can be observed that number of minor differences in the way you set up journal alerts for the popular journal databases like EBSCOhost, Web of Science and Proquest. With each user can select how frequently and how long the alert should for, and whether to receive brief or detailed records. In fact, there can be all databases can have a guide to setting up alerts. In case, a reader/ researcher is not confident how to setup an alter, he can access to database help pages or technical support. For instance, Proquest has given detailed disruptions on how to set up an alert for a publication and on managing alerts.

\section{CONCLUSION}

Social Media has provided strong opportunity to access latest information, interact with peers and serendipity in building as well as in providing information services. The applications and use of web tools and technologies are becoming central to knowledge building process which facilitates researchers and scientists digitally connected any time anywhere. Electronic network and social networking plays significant roles in delivering / exchange of information for the promotion of academic progress, research and development and in delivering modern library services.

International Journal of Research -GRANTHAALAYAH 
Web Tools and Technologies to Increase Citation Frequency by Use of Social Media: An Appraisal

The higher education, library and information centre and services in general and research in particular has been highly influenced by social media and networks. The creation and promotion of virtual learning environment groups, segments, have come in to existence by participants to interact freely and exchange their experience, new research findings, and insights into their given subject field. To conclude, it logical, reasonably justified, encouraging in using social media and social network for academic activities in the present knowledge society. However, there is need to conduct qualitative and quantitative research periodically and in the use and application of innovative tools and techniques of social media in the library and information centres and its services in the knowledge society

\section{SOURCES OF FUNDING}

This research received no specific grant from any funding agency in the public, commercial, or not-for-profit sectors.

\section{CONFLICT OF INTEREST}

The author have declared that no competing interests exist.

\section{ACKNOWLEDGMENT}

None.

\section{REFERENCES}

[1] Ali, K. S., and Khan, Khaisar M., (2017, April). Emerging Web Based Technologies for Library and Information Services in the Knowledge Era, National Level Conference on Professionalism in Library and Information Services for User Empowerment: Opportunities and Challenges, Mangalore University, pp. 503-510

[2] Ebrahim, N. A., Salehi, H., Embi, M. A., Tanha, F. H., Gholizadeh, H., Motahar, S. M., \& Ordi, A. (2013). Effective Strategies for Increasing Citation Frequency. International Education Studies,6(11). doi:10.5539/ies. v6n11p93

[3] Ebrahim, N. A., Gholizadeh, H., \& Lugmayr, A. (2017). Maximized Research Impact: An Effective Strategies for Increasing Citations. Malaysia: International Ambient Media Association.

[4] Fitzgerald, R., \& Radmanesh, A. (2014). Social Media and Research Visibility. American Journal of Neuroradiology,36(4), 637-637. doi:10.3174/ajnr. a4054

[5] Fooladi, M., Salehi, H., Yunus, M. M., Farhadi, M., Chadegani, A. A., Farhadi, H., \& Ebrahim, N. A. (2013). Does Criticisms Overcome the Praises of Journal Impact Factor? Asian Social Science,9(5). doi:10.5539/ass. v9n5p176

[6] Gandhi, S. M. (2014). Incorporating Social Media In Research And Academics. International Journal on Information Sciences and Computing,8(2), 7-9. doi:10.18000/ijisac.50146

[7] Kumari H., A., Ali, K. S., Mahadevamurthy, M., \& Hydarali. (2013). Use of social media among dental students of Farooqia Dental College, Mysore: A study. In International Conference on Open Access-Scholarly Communication Reincarnated: A Futuristic Approach (pp. 573-579). Bangalore: Bangalore University.

[8] Maccallum, C. J., \& Parthasarathy, H. (2006). Open Access Increases Citation Rate. PLoS Biology,4(5). doi: 10.1371/journal.pbio.0040176

[9] Mutum, D. S. (2015). Social Media for Researchers \& Online Personal Branding (2nd ed.). Malaysia

[10] Norman, E. R. (2012). Maximizing Journal Article Citation Online: Readers, Robots, and Research Visibility. Politics \& Policy,40(1), 1-12. doi:10.1111/j.1747-1346.2011. 00342.x

[11] Social media. (2020, September 18). Retrieved from https://en.wikipedia.org/wiki/Social_media 